\title{
Los inmigrantes alemanes y la 'prehistoria' del socialismo argentino (1888-1894)
}

\author{
German immigrants and "prehistory" of socialism Argentina \\ (1888-1894)
}

\author{
Lucas Poy* \\ Daniel Gaido**
}

\section{RESUMEN}

En las últimas décadas, las investigaciones sobre los orígenes del movimiento obrero en Argentina han conocido un importante desarollo. Recientemente se ha producido una saludable renovación del interés por estudiar las corrientes políticas que intervinieron en el seno del movimiento obrero. Con la intención de contribuir a esos enfoques, este trabajo analiza el proceso de formación de los agrupamientos socialistas en nuestro país, un proceso en el cual los inmigrantes alemanes jugaron un papel fundamental. En un contexto de crisis económica y política sin recedentes, y en el marco de una agitación huelguística que alarmó a las clases dominantes, un grupo de militantes alemanes, muchos de los cuales tenían vínculos con el socialismo de su país, se comprometió en un trabajo de organización y divulgación del marxismo. Usando materiales de archivo en alemán y en español hasta ahora inexplorados, nos proponemos realizar algunas contribuciones a la historia del papel desempeñado por los militantes socialistas en el contexto de la crisis de 1890

PALAVRAS-CHAVE: Socialismo argentino. Marxismo. Juan B. Justo. Germán AveLallemant.

\section{ABSTRACT}

In recent decades, research on the origins of the labor movement in Argentina has known an important development. In the last years there has been a healthy resurgence of interest in analyzing the political currents that developed within the labor movement. Willing to contribute to this perspective, this paper discusses the formation of the first socialist groups in Buenos Aires, a process in which the German immigrants played a key role. In a context of economic and political turmoil, and among a wave of labor actions that alarmed the ruling classes, a group of German activists many of whom had ties with socialism in their home country contributed to the development, organization, and dissemination of Marxism. Using German and Spanish archival materials so far unexplored we intend to make some contributions to a history of the role played by socialist militants at the juncture of the crisis of 1890.

KEY-WORDS: Socialism argentina ; Marxism; J uan B. J usto Germán Ave-Lallemant.

\footnotetext{
*Docente del Departamento de Historia, Universidad de Buenos Aires. Becario doctoral del CONICET en el Instituto Gino Germani (UBA). Dirección electrónica: lucaspoy@gmail.com

** Profesor de la Escuela de Historia, Universidad Nacional de Córdoba. Investigador del CONICET en el Centro de Estudios Avanzados (UNC). Dirección electrónica: danielgaid@gmail.com
} 


\section{Presentación. los Orígenes del Socialismo Argentino como Problema Historiográfico}

La consolidación del poder estatal que siguió al enfrentamiento militar de 1880 aseguró en la Argentina las condiciones de un desarrollo económico basado en el flujo de inversiones extranjeras y la llegada masiva de inmigrantes europeos. Hacia fines de la década, no obstante, comenzaron a hacerse evidentes los límites de un progreso que parecía "indefinido": se frenó la llegada de capitales externos y la estabilidad política volvió a dar serias evidencias de crisis. La concentración de los inmigrantes en las ciudades, consecuencia de la estructura agraria del país, había contribuido por otra parte al surgimiento de un naciente proletariado. Si en la década de 1870 el enviado de la Asociación Internacional de Trabajadores estaba aún en condiciones de escribirle a Karl Marx que las posibilidades de ascenso social existentes en el país hacían imposible cualquier intento de organización de los trabajadores, en la segunda mitad de la década de 1880 las cosas habían cambiado. Los años 1888-1889 fueron testigos del primer desarrollo huelguístico de ciertas proporciones en la ciudad de Buenos Aires; el año 1890 conoció la irrupción de la clase obrera en la escena pública del país. ${ }^{3}$

El proceso de conformación del movimiento obrero en nuestro país contó con la participación destacada de un núcleo de socialistas de origen alemán que habían llegado a la Argentina como consecuencia de la legislación represiva promulgada por Bismarck en la década anterior. A pesar de que en numerosos trabajos se han hecho menciones a esta etapa "prehistórica" del socialismo argentino, el proceso permanece aún escasamente explorado en su complejidad. Durante buena parte del siglo XX, la historia del socialismo concitó escasa atención por parte de la historiografía profesional argentina y los trabajos existentes fueron obra casi exclusiva de militantes o dirigentes de esa misma corriente (ODDONE, 1934; CÚNEO, 1943; DICKMANN, 1949, entre otros). De todas formas, el rol jugado por los socialistas alemanes en la etapa previa a la fundación del partido permaneció en general al margen de las inquietudes incluso en esta literatura, más preocupada por reivindicar la figura de J uan B. J usto y por lo tanto por examinar la historia del socialismo tomando como punto de partida la aparición en escena del fundador de La Vanguardia (CAMARERO; HERRERA, 2005). Recién a fines de la década de 1960, en el marco de una discusión entre el Partido Comunista Argentino y grupos disidentes, aparecieron un par de trabajos que reivindicaron a Germán Avé-Lallemant (1835/36-1910) como el principal teórico de un marxismo

\footnotetext{
3 Una versión de este trabajo fue presentada en las XII J ornadas Interescuelas/Departamentos de Historia, Universidad Nacional del Comahue, San Carlos de Bariloche (Argentina), octubre de 2009.
} 
"ortodoxo" y revolucionario que habría cobrado fuerza durante los primeros años de la década de 1890 para perder terreno luego ante el avance del reformismo de los líderes del Partido Socialista (RATZER, 1970; PASO, 1974).

Si bien contribuyó a revitalizar el campo de la historia de los trabajadores, la importante renovación historiográfica que tuvo lugar luego del retorno de la democracia en 1983 no profundizó un análisis de la historia política del socialismo. Fue un trabajo anclado en la historia intelectual más que en la historia social (ARICÓ, 1999) el que marcó una época en cuanto al análisis del socialismo argentino. Su ensayo dedicado al fundador y principal dirigente del Partido Socialista planteaba una reivindicación de la figura de J uan B. Justo, en tanto lo consideraba capaz de haber articulado una "hipótesis" original para la traducción del socialismo a la problemática de la Argentina de principios de siglo: tampoco profundizaba, de todas formas, en un análisis sobre el período previo. ${ }^{4}$

Un conjunto de trabajos publicados en los últimos años dieron cuenta de la necesidad de complejizar el análisis con el objetivo de estudiar el proceso de conformación del socialismo en nuestro país atendiendo a las diferencias y polémicas surgidas en el seno del núcleo socialista y en el contexto del socialismo internacional, evitando al mismo tiempo interpretaciones anacrónicas. (MARTÍNEZ MAZZOLA, 2004; TARCUS, 2004, 2007a, 2007b; ZELLER, 2007; ZELLER; TARCUS, 2008). Esta reactivación del campo académico constituye un avance auspicioso y plantea nuevos interrogantes al cual este artículo pretende contribuir. A partir del trabajo con fuentes documentales nos proponemos hacer algunos aportes a una historia del papel jugado por los primeros militantes socialistas en la coyuntura de la crisis de 1890, poniendo especial énfasis en la necesidad de vincular esta historia política con el proceso de movilización y conformación de la naciente clase obrera.

\section{Los Inmigrantes Socialistas Alemanes en La Década de 1880. El Verein Vorwärts y su Periódico}

Si bien los primeros introductores del marxismo en la Argentina fueron los exiliados franceses de la Comuna de París que llegaron al país en la década de 1870, fue recién en la década siguiente cuando se conformaron las primeras organizaciones permanentes, fundamentalmente gracias a los esfuerzos de la comunidad alemana, que incluía a más de cien exiliados por causa de las leyes anti-socialistas de Bismarck. La actividad organizada de los socialistas alemanes en nuestro país comenzó en 1882,

\footnotetext{
${ }^{4}$ El propio Aricó (1999, p. 61-62) así lo ponía de manifiesto: “Aún falta un estudio detenido sobre el papel desempeñado por la emigración alemana en la formación del socialismo latinoamericano".
} 
cuando un grupo de exiliados formaron el Verein Vorwärts (Asociación "Adelante”) siguiendo la iniciativa de Karl Mücke, quien había trabajado en la redacción de Der Sozialdemokrat, el principal órgano del SPD alemán (TARCUS, 2008, p. 446). El 2 de octubre de 1886 el grupo comenzó a editar un periódico semanal, llamado Vorwärts. Organ für die Interessen des arbeitenden Volkes [Adelante. Órgano para la defensa de los intereses del pueblo trabajador], del cual aparecerían 696 números hasta su desaparición en marzo de 1901.

Como han señalado Horacio Tarcus y J essica Zeller, el papel jugado por los socialistas alemanes nucleados en el Verein Vorwärts permanece aún velado por una suerte de "mito de los orígenes" al que ha contribuido la historiografía socialista. En realidad, la escasez de investigaciones históricas sobre este grupo tiene que ver con la disponibilidad del material documental: hasta el reciente descubrimiento de una colección microfilmada del Vorwärts en la UNLP, el único trabajo era el realizado por el checo Jan Klima (1974) a partir de los materiales llevados a Europa por inmigrantes retornados. Tarcus (2007b, p. 133-144) discutió las conclusiones de Klima, señalando que el aparente "eclecticismo" de la ideología del Vorwärts no respondía a una peculiaridad latinoamericana sino que era un fenómeno propio de la socialdemocracia de la época. J essica Zeller (2007), que trabajó el material en alemán, ha mostrado la tensión siempre existente en su seno entre la militancia socialista y las actividades sociales para inmigrantes alemanes.

Ya las primeras reseñas históricas sobre los orígenes del movimiento obrero y socialista en nuestro país, elaboradas por militantes que habían sido protagonistas del proceso, subrayaban este carácter ambiguo del rol jugado por el Verein. En 1916, Augusto Kühn había señalado que, si bien era cierto que desde la fundación de la Asociación el "hilo del movimiento" socialista ya no se interrumpió, el papel del Vorwärts no debía exagerarse: "Algunos atribuyen a este club una serie de grandes méritos, mientras otros no le reconocen ninguno. La verdad está en medio de estos dos extremos (KÜHN, 1916).

Diez años, más tarde - cuando ya revistaba en las filas del Partido ComunistaKühn publicó una nueva reseña histórica en la cual sostenía una interpretación similar. Allí sostenía que el Verein había "gozado durante mucho tiempo de una reputación envidiable", forjándose a partir de los escritos posteriores de algunos dirigentes socialistas "una leyenda que le atribuye méritos que no tiene, o que son exagerados", dado que sus aportes no habían ido más allá de "una conferencia de vez en cuando, la venta de un poco de literatura socialista y cierta liberalidad en la cesión de su local para los organismos obreros". Lo más positivo de su acción, señalaba Kühn, había sido la 
publicación de su periódico, y particularmente el rol jugado por el mismo en la coyuntura previa e inmediatamente posterior a 1890 (KÜHN, 1926).

En realidad, conceptos similares habían aparecido, treinta años antes, en una serie de artículos de enorme interés que constituyen la primera $-\mathrm{y}$ aún inédita en español - reseña de la historia del movimiento obrero y socialista argentino publicada en Vorwärts. La serie, que apareció en mayo de 1896 y fue escrita probablemente por Germán Avé-Lallemant, planteaba que “aunque el Verein Vorwärts siempre conservó el carácter de un club de entretenimiento, ejerció - sobre todo a través de su periódico, que representaba, por así decirlo, su espíritu- una influencia sobre el movimiento obrero local que no debe subestimarse" fundamentalmente en los años previos a la crisis de $1890 .^{5}$

\section{Agitación Obrera y Actividad Socialista (1888-1889)}

Teniendo en cuenta los señalamientos realizados por los propios inmigrantes alemanes en sus elaboraciones posteriores, consideramos que un estudio del desarrollo del socialismo en nuestro país hacia fines de la década de 1880 y comienzos de la siguiente debe ponerse en relación con el importante proceso de movilización y agitación que experimentó el mundo de los trabajadores urbanos de la ciudad de Buenos Aires a partir de 1887, en un contexto de deterioro del poder adquisitivo del salario, devaluación de la moneda y creciente crisis económica.

Si todo el país había conocido un gran crecimiento de población a partir de la inmigración masiva que tuvo lugar en la década de 1880, el fenómeno era particularmente notable en la ciudad de Buenos Aires: entre 1869 y 1887 la población de la ciudad creció a una tasa anual del 7,3\%, un ritmo superior incluso al de urbes de enorme crecimiento como Chicago, Boston o San Francisco. Según el censo municipal realizado en 1887, vivían en la ciudad 433.375 personas, de las cuales el 52,7\% eran extranjeras. El imponente crecimiento de la ciudad había convertido a la construcción en una de las principales ramas de la economía: en 1887 el Censo registraba a más de 10.000 personas ocupadas como albañiles, pero es importante sumar también a los trabajadores ocupados en diversas obras públicas y privadas como las de remodelación y construcción portuarias -particularmente la canalización del Riachuelo y la construcción del Puerto Madero-, instalación de cloacas y alumbrado, etc. Alrededor

5 Kurze Geschichte der Arbeiterbewegung in Argentinien, Vorwärts, n. 499, 15 ago. 1896. p. 1; Vorwärts, n. 502, 5 set. 1896. p. 1-2; Vorwärts, n. 504, 19 set.1896. p. 1; Vorwärts, n. 505, 26 set.1896. p. 1; Vorwärts, n. 506, 3 out. 1896. p. 1; Vorwärts, n. 508, 17 out. 1896. p. 1-2. 
de 10.000 personas se desempeñaban como carpinteros, ocupados tanto en la industria de la construcción como en la producción para el consumo (FALCÓN, 1984).

Un rol fundamental, por su cantidad y por el lugar que ocupaban en el contexto de la economía exportadora, era el jugado por los trabajadores de los transportes y diversos servicios. A los trabajadores ferroviarios, en creciente expansión dado el aumento de las líneas férreas, debemos agregar a los casi cinco mil carreros y más de dos mil cocheros que existían en 1887. El crecimiento de la ciudad, por otra parte, había generado un mercado para distintos productos que eran elaborados en pequeños talleres y fábricas. Según una estadística realizada para la Unión Industrial en 1887, había unos 400 establecimientos que empleaban a 11.000 personas (DORFMAN, 1986, p. 200) aunque las cifras debe ser tomadas con cuidado: el censo nacional realizado en 1895 arrojaba un total de más de 8.400 talleres que empleaban a unas 70.000 personas, lo cual muestra, más allá del lógico aumento, una evidente diferencia en el modo de recabar los datos. En cualquier caso, es importante señalar que si bien había fábricas que empleaban a más de un centenar de obreros, el promedio de trabajadores por establecimiento era todavía reducido. Las principales ramas eran la industria de la alimentación (panaderías, confiterías, licorerías, etc) y la confección (zapateros, sastres, sombrereros, entre otros), aunque también tenían su importancia ciertas industrias livianas: existían ya en la ciudad varios miles de trabajadores metalúrgicos y herreros que jugarían un papel importante en la agitación del período inmediatamente posterior.

Durante la segunda parte de la década de 1880 tuvo lugar un profundo proceso de encarecimiento del costo de la vida, que resulta esencial para comprender la movilización de los trabajadores. La ley 1130, sancionada el 25 de noviembre de 1881, había establecido que un peso oro sería equivalente a 1,033 de los antiguos "pesos fuertes" y a 1,6129 gramos de oro, al igual que la libra esterlina. A partir de enero de 1883 un peso oro, que correspondía aproximadamente a 25 de los antiguos pesos "moneda corriente", pasó a ser equivalente a un peso de la nueva moneda, llamada "peso moneda nacional". La convertibilidad, no obstante, no duró más que dos años, y a partir de 1885 el peso moneda nacional comenzó a devaluarse. A comienzos de 1888, la moneda nacional ya se había depreciado en un 45\%, lo que provocó una fuerte carestía que impactó directamente en el bolsillo de los trabajadores.

La chispa que dio inicio al ciclo de huelgas no fue provocada, sin embargo, por un reclamo salarial, sino por el rechazo a un intento de imponer una regimentación sobre el personal de servicio: en enero de 1888 estalló un movimiento de protesta del llamado "personal doméstico" que se transformó en una auténtica huelga generalizada 
de todo el personal de hoteles y restaurantes de la ciudad, y pocos días después se extendió a los cocheros públicos y privados, adquiriendo una extensión preocupante para los principales observadores de la elite y el propio gobierno. ${ }^{6}$ Hacia fines de mes, estalló una huelga de panaderos, en reclamo de aumento salarial y otras reivindicaciones. A fines de octubre del mismo año comenzó un nuevo período de agitación obrera, caracterizado por la movilización de trabajadores ferroviarios, empleados de pequeños establecimientos metalúrgicos y otros sectores semiartesanales, principalmente zapateros. La mayor profundidad de los conflictos, en un contexto en el cual ya comenzaban a hacerse evidentes los síntomas de la crisis económica, puso al conflicto social en primer plano y dio lugar a una importante represión policial de manifestaciones de obreros en huelga. ${ }^{7} \mathrm{Si}$ los conflictos de principios de año ya habían llamado la atención de amplios sectores de la clase dominante, el estallido huelguístico de la primavera de 1888, más extendido y generalizado que el del verano, colocó en primer plano la cuestión de la legitimidad de la protesta de un sector social que hacía su aparición en la escena pública. ${ }^{8}$

Aún más importante para nuestro tema de análisis es la aparición, en las agitadas semanas de octubre y noviembre de 1888, de la primera campaña pública de denuncia contra los socialistas alemanes, que serían acusados por miembros de la elite como responsables del movimiento huelguístico. El tema, prácticamente inexplorado por la historiografía, ya aparecía señalado en la citada reseña histórica publicada en Vorwärts en 1896. En efecto, mientras algunos periódicos opositores al juarismo seguían viendo con cierta condescendencia al movimiento huelguístico, considerando que sus reclamos eran legítimos y que no estaban provocados por motivaciones políticas de ninguna clase, otras publicaciones afines al gobierno lanzaron una campaña de corte sensacionalista en contra de los socialistas de origen alemán y su periódico.

\footnotetext{
${ }^{6}$ La "huelga de los domésticos" fue vista con simpatía por la prensa antijuarista e incluso por un sector del propio grupo gobernante, lo que obligó al intendente municipal a retirar eventualmente la disposición. Ver "El ukase municipal", La Nación, 22/01/ 1888; “Todavía la ordenanza”, La Nación, 24 jan.1888; "La huelga", La Prensa, 25 jan. 1888. La opinión de la prensa "situacionista" en La Tribuna Nacional, 22 jan. 1888.

${ }^{7}$ Los conflictos se pueden seguir en detalle en la prensa periódica, que dedicó un amplio espacio a su cobertura desde fines de octubre de 1888.

${ }^{8}$ Ver, entre muchos otros: "La semana”, El Censor, 29 out. 1888; “Cómo se combaten las huelgas", La Nación, 02 nov. 1888; "Patrones y obreros. Derechos y abusos", La Nación, 10 nov. 1888; "Las huelgas", Sud-América, 10 nov. 1888; “Las clases obreras en nuestro país. Inmigración y crédito”, El Nacional, 12 dez. 1888.
} 
Hoy la causa de todas las huelgas es conocida - decía una nota editorial de Figaro-. Existe, aunque parezca increíble, organizado el socialismo en la Argentina. Tiene hasta un órgano de publicidad, que difunde en las clases obreras las ideas, cuyo alcance hemos podido apreciar en estos últimos días, en que un gran número de talleres y fábricas han debido suspender sus trabajos para escuchar las exigencias de sus operarios y peones. ${ }^{9}$

El editorial incluía una reivindicación de los inmigrantes latinos, por oposición a los politizados trabajadores alemanes, y concluía con un firme llamado a la represión.

Un alemán me tradujo los sueltos del Vorwaerts, señalados por el caballero en cuestión: esto es tremendo, estupendo, horripilante! [...] La inmigración latina, los tipos de la Europa meridional, donde todo es calor y luz, vida y alegría, esto es lo que nos conviene [...] Mañana, si por confianza de nuestras autoridades, o porque quieran dejar que la libertad exista hasta el abuso, llegamos a ser víctimas de un levantamiento encabezado por la asociación que parece dirigir a la clase obrera, será preciso emplear medidas tremendas que pueden evitarse desde ahora, yendo derecho a la causa y destruyéndola, cuando empieza a manifestarse. ${ }^{10}$

En líneas similares se pronunciaba Sud-América, el principal diario oficialista. Luego de algunas referencias menores que trataban de soslayar la gravedad de los conflictos, se sumó a mediados de noviembre a la campaña de denuncias contra los socialistas, con un curioso artículo que personificaba al Verein como un seguidor del propio Karl Marx:

Desgraciadamente habíamos contado sin herr Worwaertz (sic), o sea el señor Adelante, quien se nos deja caer ahora, con el propósito de hacer flamear bien alto el trapo rojo, símbolo del socialismo... y de la locura. Así es: el caballero Worwaertz, ferviente discípulo a lo que parece de Karl Marx, el fundador de la Internacional, ha lanzado su proclama - en alemán, y se imagina que todo el cosmopolitismo obrero se halla pronto a seguirle ebrio de entusiasmo!11

Al igual que Figaro, reclamaba enérgicas medidas represivas, antes de que fuera "demasiado tarde", en una nota editorial que es casi una premonición de la Ley de Residencia de 1902:

En Europa cuando un hombre tiende con sus doctrinas o su modo de ser a perturbar la paz social, el gobierno le notifica con mucha cortesía para que tenga a bien preparar su maleta (si tiene una) y prepararse él mismo para respirar los aires de la frontera.

Nuestras leyes se oponen a la entrada de los inmigrantes sexagenarios o inválidos y las autoridades saben aplicar la multa a los agentes o capitanes de vapor que dejan desembarcar a esos inútiles. ¿Por qué no se agrega un artículo que diga más o menos esto:

\footnotetext{
${ }^{9}$ El socialismo y las huelgas, Figaro, 14 nov. 1888. p. 1.

${ }^{10}$ Ibid.

${ }^{11}$ El socialismo en Buenos Aires, Sud-América, 15 nov. 1888. p. 1.
} 
Art... Todo individuo extranjero que por sus palabras u otros medios, tienda a hacer propaganda capaz de alterar el orden social, será expulsado del país dentro del término de [...] si es que en la ley penal no se encontrase su equivalente. ${ }^{12}$

La campaña trascendió las páginas de los periódicos y llegó hasta el propio Congreso: allí, tal como recordaba Lallemant ocho años más tarde, "tuvo lugar un debate antisocialista virulento" en el cual "el diputado Costa reclamó medidas enérgicas contra el confiscado periódico socialista Vorwärts" y los "viciosos discursos del club homónimo". ${ }^{13}$

En 1889 se incrementó la agitación obrera, conforme se agravaba la crisis económica y con ella la carestía y la depreciación de los salarios. Diversos trabajos han calculado el estallido de entre diez y quince huelgas de importancia, que afectaron a sectores fundamentales para la economía argentina, como el portuario y el ferroviario. Trabajadores de ramas de la producción menos centrales, pero que antes no habían participado en movimientos gremiales (peluqueros, sastres, obreros gráficos de Peuser), también se volcaron a la lucha, en reclamo de aumento salarial y otras reivindicaciones (MAROTTA, 1975, p. 66-90; ZARAGOZA, 1996, p. 117-120).

Hacia fines del invierno, mientras comenzaba a crecer la inquietud política en sectores de la clase dominante ante la profundización de la crisis económica, el ascenso huelguístico se intensificó. Ahora se sentía también en sectores de fundamental importancia para la economía exportadora. Los trabajadores de la obra del Riachuelo habían ido a la huelga a mediados de enero, en reclamo de aumento salarial. A comienzos de agosto más de dos mil marineros, pilotos y trabajadores de los muelles volvieron a declararse en huelga. El movimiento se extendió cuando se plegaron los carpinteros y calafateadores de los astilleros, y un mes más tarde entró en conflicto el sector ferroviario, con huelgas de obreros de la estación Retiro, los talleres de Sola y el depósito de Campana. Durante el mismo mes de septiembre, una huelga de albañiles se extendió rápidamente por todo el gremio: una asamblea realizada en Plaza Constitución llegó a reunir a quince mil trabajadores (ZARAGOZA, 1996, p. 118-119).

En el marco de este despliegue huelguístico, varias reuniones de coordinación entre los huelguistas - e incluso entre trabajadores y pequeños patrones ${ }^{14}{ }_{-}$se realizaron en el local del Verein Vorwärts, que comenzaba a convertirse en el centro de

\footnotetext{
12 Todavía el socialismo, Sud-América, 17 nov. 1888. p. 1.

13 Kurze Geschichte..., Vorwärts, n. 499, 15 ago. 1896. p 1. Los socialistas respondieron desde las páginas de su periódico, argumentando que no eran ellos, sino los capitalistas, los que provocaban las huelgas. Ver Die Streiks und die Sozialisten, Vorwärts, n. 100, 17 nov. 1888. p. 1.

${ }^{14}$ Guerra al capital, La Nación, 27 nov. 1888. La versión socialista en Ein Arbeitertag in Buenos Aires, Vorwärts, n. 102, 1 dez. 1888. p. 1.
} 
la actividad organizativa del incipiente movimiento obrero de la ciudad. En algunos de los conflictos, además, los socialistas jugaron un papel fundamental en la organización gremial: es el caso de los carpinteros, cuyo principal dirigente era el socialista Carlos Mauli. En este contexto, la prensa periódica de la época -y también importantes círculos gobernantes-, que veía con preocupación el ascenso obrero, profundizó en 1889 la campaña de denuncia de los socialistas alemanes que ya había iniciado el año anterior. ${ }^{15}$

Por otra parte, es fundamental analizar el papel jugado por los socialistas en relación con otras corrientes que intervenían en el movimiento huelguístico. Gonzalo Zaragoza ha señalado agudamente la importancia jugada por Enrico Malatesta y un grupo de inmigrantes anarquistas italianos en esa coyuntura crítica de ascenso obrero que tuvo lugar en Buenos Aires en 1888 y 1889. Este predominio de los anarquistas partidarios de la organización y de la lucha gremial permitió una importante acción común con los inmigrantes socialistas alemanes, que se vincularon de esta forma con un movimiento popular en auge. Ya en enero de 1888, el diario La Nación informaba de una reunión conjunta de "socialistas, anarquistas y revolucionarios", y en marzo del mismo año - luego de los conflictos de enero y febrero- una conmemoración de la Comuna de París en el club Vorwärts fue disuelta por la policía como actividad subversiva, deteniendo a seis anarquistas que quedaron en libertad al día siguiente. El 16 de abril de 1888 se realizó una reunión de anarquistas y socialistas en el club Vorwärts, en la cual los socialistas alemanes propusieron la conformación de una federación de sindicatos abierta a todas las ideologías. ${ }^{16}$ A comienzos de junio, una nueva reunión en el salón de los socialistas alemanes, "en que están presentes Malatesta, Rabassa, Morales y Mattei, se acepta la idea de la federación estilo anarquista, es decir, respetando claramente la autonomía de las unidades federadas. Se designa un comité 'de buenos y activos elementos' para poner en práctica la idea y se acuerda celebrar el aniversario de la toma de la Bastilla el 14 de julio" (ZARAGOZA, 1996, p. 119).

\section{De un 1o de Mayo a Otro (1890-1891)}

En julio de 1889 se reunía en París un Congreso Internacional de Trabajadores, con alrededor de 400 delegados de unos 20 países, que resolvió fundar la Segunda

\footnotetext{
${ }^{15}$ En noviembre de 1889, dos dirigentes del Verein fueron detenidos por la publicación de una denuncia a la política presidencial. Ver Anklage des Praesidenten Celman gegen den Vorwärts, Vorwärts, n. 150, 10 nov. 1889. p. 1.

${ }^{16}$ Vorwärts, n. 70, 21 abr. 1888. p.3.
} 
Internacional. ${ }^{17}$ Las noticias de lo resuelto en París llegaban a una Buenos Aires conmovida por la movilización y el ascenso de los sectores populares, en el marco de lo cual se venía dando una acción conjunta entre diversas corrientes políticas. En este contexto, hacia fines de 1889 comenzaron a darse pasos comunes entre socialistas, anarquistas y un sector de republicanos mazzinistas de origen italiano para la organización de una manifestación política el primero de mayo del año siguiente. Los socialistas alemanes tuvieron un papel destacado en la conformación de un Comité Internacional Obrero que tomó la tarea de organizar la manifestación y reclamó la necesidad de establecer una federación obrera, la publicación de un "periódico en defensa de la clase trabajadora" y la entrega de un petitorio al Congreso con el objetivo de exigir la aprobación de una serie de "leyes protectoras de la clase obrera". ${ }^{18}$

La manifestación se celebró, finalmente, el primero de mayo de 1890, en el Prado Español, y concitó la atención de la prensa de la época; no nos extenderemos aquí en un análisis del episodio, que ha sido abordado en diversos trabajos. ${ }^{19}$ Nos interesa, particularmente, analizar el proceso que se desarrolló en los agitados meses posteriores, y que llevaron a que eventualmente fuera imposible la organización de un acto unificado el $1^{o}$ de mayo del año siguiente. Es preciso, para ello, atender a la dinámica del movimiento popular, al retroceso de las luchas obreras en el contexto de la profundización de la crisis, a la fuerte represión estatal que trajo como consecuencia el estado de sitio declarado luego de la revolución del parque y, last but not least, a la lucha política y teórica entre socialistas y anarquistas.

Después de la manifestación del 10 de mayo, el movimiento no logró seguir profundizándose: en cierta medida se debió al estallido de la revolución del Parque, hacia fines de julio de 1890. Es importante señalar, de todas formas, que el límite alcanzado por el movimiento se vincula también con el relativo declive de las huelgas y movilizaciones obreras - en un contexto de depresión económica general-, que se profundizaría al año siguiente. Por otra parte, la acción conjunta de socialistas y anarquistas que tuvo lugar durante 1888 y 1889 se veía ahora fuertemente limitada por

17 Diego Abad de Santillán Papers: A (Argentina) Informe al Congreso Socialista de París de 1889, IISG. Protokoll des Internationalen Arbeiter-Congresses zu Paris, abgehalten vom 14. bis 20. J uli 1889. Nünberg: Wölein, 1890.

18 En las semanas previas a la manifestación del 1o de mayo, apareció en Vorwärts una serie de artículos escritos por Germán Ave-Lallemant en los cuales el ingeniero alemán realizaba una reseña histórica de la sociedad argentina desde la época colonial hasta los gobiernos de Mitre y Roca. Se trata de un material de notable interés que anticipa los artículos publicados por Lallemant en El Obrero al año siguiente. Germán Avé Lallemant, "Beiträge zu einer Kulturgeschichte Argentiniens: Historische Studie von G.A.L.," Vorwärts, n. 174, 26 abr. 1890, n. 176, 10 maio 1890, y n. 177, 17 maio 1890.

${ }^{19}$ La mejor fuente es el trabajo de Kühn (1916). El tema también es analizado por Tarcus (2007b, p. 163-167) y Marotta (1975, p. 94-99), entre otros. 
el predominio que comenzaron a ganar los anarquistas individualistas: en buena medida, la movilización del 1o de mayo fue menos el punto de partida de un desarrollo conjunto de la clase obrera que la última acción común del período previo, marcado por el ascenso obrero.

Apenas unos días después de la manifestación del Prado Español aparecía el primer número de El Perseguido, órgano que dominaría toda una etapa del anarquismo argentino, caracterizada por el predominio de los anarquistas individualistas. En la segunda mitad de 1890 los socialistas encontraron dificultades para dar constitución real a la federación obrera - constituida formalmente a fines de junio- y al periódico impulsados en las jornadas de mayo. Recién en diciembre vio la luz El Obrero, órgano de la federación y editado por Germán Avé-Lallemant. En otros trabajos hemos desarrollado un análisis de este periódico - del cual aparecieron 88 ediciones, entre el 12 de diciembre de 1890 y el 14 de septiembre de 1892- que constituye un paso fundamental para la propaganda socialista en Argentina. No debe soslayarse, sin embargo, que su aparición tuvo lugar en un momento en el cual la influencia de los socialistas comenzaba a debilitarse en un contexto de profundización de la crisis económica y avance de los grupos individualistas.

En efecto, en los primeros días de 1891 - es decir, pocas semanas después de la aparición del primer número de El Obrero-El Perseguido trazaba con satisfacción un balance de los últimos meses, durante los cuales consideraba que se había producido un crecimiento de la tendencia anarquista:

\begin{abstract}
Con el año 1890, el Comunismo anárquico, ha tomado en esta República un incremento que no había tomado otros años [...]. [H]an sido una profusión de grupos que se han constituido en la capital y en las provincias, y hacemos notar que todos estos grupos se han constituido por afinidades emancipatorias de todas aquellas prácticas autoritarias que algunos anarquistas habían practicado hasta producirse este movimiento. [...] Los grupos Tierra y Libertad, El Perseguido, Los Errantes y algunos otros que no recuerdo sus nombres, se presentaron al local del partido obrero para sostener unas conferencias de controversia que se habían organizado de común acuerdo entre ambas partes. De estas conferencias nuestros compañeros salieron victoriosos, y no sólo entusiasmaron a la asamblea, sino que hasta de los mismos organizadores y oradores del partido obrero han venido a nuestras ideas y de tal modo que, estos, hoy son de los que trabajan con mayor actividad para extender la propaganda comunista anárquica. ${ }^{20}$
\end{abstract}

Es en este contexto que hay que analizar la polémica política entablada por los socialistas nucleados en El Obrero -y particularmente por Germán Ave-Lallemant-

\footnotetext{
${ }^{20}$ Nuestro aguinaldo, El Perseguido, n. 13, 6 jan 1891.
} 
con los anarquistas, en los meses inmediatamente anteriores al 1o de mayo de 1891. En efecto, el interés por los artículos dedicados al problema agrario o a la caracterización de la formación social argentina ha hecho que muchos analistas descuiden las intervenciones más propiamente políticas de Lallemant en El Obrero. Estas últimas, por otra parte, no pueden estudiarse desde un punto de vista puramente intelectual o doctrinario, sino que deben ser puestas en relación con este crecimiento de los anarquistas individualistas y con la seria dificultad que encontraban los socialistas para elaborar un marco de acción común en un contexto de reflujo de las luchas. ${ }^{21}$

Mientras se profundizaba la polémica desde las páginas de El Obrero y El Perseguido - y en "conferencias de controversia" impulsadas por los anarquistas, en las cuales los socialistas eran renuentes a participar-, se realizaron algunas reuniones para intentar organizar una manifestación unificada el ํo de Mayo de 1891.22 Como era de preverse, el intento fracasó rápidamente: la contradicción entre el grupo de socialistas que quería incluir en las resoluciones una "tirada extraordinaria" de El Obrero y los anarquistas individualistas, que reclamaban convocar a una huelga general y "atentar los almacenes", era demasiado aguda, y el contexto de movilización obrera ya había entrado en un reflujo. Las diferencias se concretaron en una polémica sobre si la manifestación debía hacerse en un lugar público o cerrado y dieron lugar a una ruptura de las negociaciones. El 1 o de mayo, los anarquistas protagonizaron una manifestación en la Plaza de la Victoria que terminó con trece detenidos, mientras que los socialistas realizaron un acto reducido ("una fiesta seria y digna") en la sede del Verein Vorwärts. ${ }^{23}$

\section{Rupturas Entre los Socialistas Alemanes (1891-1893)}

La polémica entre El Obrero y los anarquistas alcanzó su punto más alto en las semanas previas al acto del $1^{0}$ de mayo de 1891. Poco después comenzaría a ponerse de manifiesto la crisis dentro del propio campo de los socialistas alemanes, que hasta entonces habían actuado de manera unificada en la formación de la incipiente

${ }^{21} \mathrm{El}$ socialismo científico y el anarquismo, El Obrero, n. 4, 17 jan. 1891. Contra el anarquismo, El Obrero, n. 13-14, 21 a 28 mar.1891. Los anarquistas y nosotros, El Obrero, n. 15, 4 abr. 1891. La democracia socialista, El Obrero, n. 16, 11 abr. 1891. Nuestra táctica, El Obrero, n. 20-23, 9 a 31 maio1891. Tarcus (2007, p. 219-224).

${ }^{22}$ Una reunión despótica, El Perseguido, n. 19, 5 abr.1891; Reuniones, El Perseguido, n. 20, 19 abr. 1891.

${ }^{23}$ Para un amplio balance de la manifestación anarquista, ver El Perseguido № 22, 17/05/1891. La crónica del acto socialista en Die Maifeier, Vorwärts, n. 227, 9 maio 1891. 
Federación Obrera. ${ }^{24}$ En efecto, el 24 de mayo el Verein Vorwärts anunció su separación de la Federación. La polémica abierta se inició un par de meses más tarde, con motivo de la realización del tan postergado Primer Congreso, celebrado el 15 de agosto de 1891. Para el Vorwärts, el problema era que no estaban dadas las condiciones para la creación de una Federación Obrera, debido a la situación de la clase trabajadora local: "El orden del día [del Congreso] estaba calculado más para una asamblea popular berlinesa que para un encuentro de trabajadores en la wild, wild South America". Los editores del Vorwärts consideraban que el intento de construir una Federación era prematuro, en tanto la clase trabajadora no estaba aún en condiciones de constituir semejante asociación. "No puede pensarse que los trabajadores de Argentina, tan heterogéneos, totalmente carentes de formación, totalmente diversos no sólo en cuanto al lenguaje, sino también en cuanto al modo de vida y la cultura, puedan hacer causa común." Lo que se planteaba, entonces, no era construir una Federación sino intentar fortalecer las organizaciones gremiales de oficio". ${ }^{25}$

La respuesta del grupo organizador de la Federación Obrera y editor de El Obrero estuvo a cargo de Germán Ave-Lallemant, quien envió al Vorwärts un artículo que fue publicado a fines de octubre, con la aclaración, por parte de los editores, de que conservaban el punto de vista original expresado en el artículo de agosto. Lallemant criticaba la postura adoptada por el Vorwärts respecto del Congreso: si bien admitía que "a pesar de los muchos sacrificios y esfuerzos que algunos camaradas han hecho por la F.O., no se han conseguido aún logros importantes," defendía el trabajo realizado y consideraba, con una argumentación propia de su estilo, que la crítica elaborada por el Vorwärts no sólo coincidía con la realizada por los anarquistas, sino que tenía la misma base teórica y filosófica. ${ }^{26}$

A comienzos de 1892, el debate volvió a tomar fuerza: luego de varios artículos breves, El Obrero editó una crítica más amplia y desarrollada a las posiciones del periódico alemán. Allí se señalaba que el problema fundamental que debía aclararse era si estaban dadas las condiciones económicas, en la Argentina de entonces, para plantearse la organización de los trabajadores: "Las condiciones económicas bajo las cuales existe en este país el proletariado debe ser el punto de partida de la propaganda.

\footnotetext{
24 Mencionada en la historiografía por Ricardo Martínez Mazzola y Horacio Tarcus, hasta ahora esta discusión había sido reconstruida exclusivamente a partir de las intervenciones escritas en El Obrero. Aquí agregamos un análisis de los artículos publicados en el Vorwärts.

${ }^{25}$ Zur Klärung!, Vorwärts, n. 242, 22 ago. 1891.

26 Betrachtungen über den Ersten Argentinischen Arbeiterkongress, Vorwärts, n. 252, 31 out. 1891. De hecho, la crítica al Congreso publicada en El Perseguido tiene muchos elementos en común con la realizada por el Vorwärts, e incluso cita las declaraciones del dirigente del Verein que se retiró del lugar. Ver “Congreso obrero”, El Perseguido, año II, n. 27, 23 ago.1891.
} 
El movimiento obrero moderno, o sea el Socialismo, nace de la organización capitalista de la producción, y se distingue esencialmente de las luchas de clase anteriores". ${ }^{27}$ Según El Obrero, planteadas las cosas en términos de un análisis materialista, no cabía duda de que en la Argentina estaban dadas las condiciones para la organización de un movimiento socialista.

El mismo día que aparecía este último artículo en El Obrero, se publicaba, en el número 265 del Vorwärts, un largo artículo dedicado a criticar a sus compatriotas de la Federación Obrera, y en particular a su "líder intelectual", es decir Germán AveLallemant. Los editores del Vorwärts insistían en que no estaban dadas las condiciones para el desarrollo del movimiento en Argentina:

Como se ha dicho ya varias veces, Argentina no es aún un Estado puramente capitalista; en consecuencia, tampoco pueden estar presentes las consecuencias que acarrea un Estado puramente capitalista. En segundo lugar, su población es tan heterogénea en cuanto al idioma y al modo de vida que también esta circunstancia se convierte en un obstáculo para el movimiento obrero. ${ }^{28}$

Para el Vorwärts, por lo tanto, El Obrero pecaba de voluntarismo, incapaz de entender que "el socialismo no se importa, no se fabrica, como tampoco se fabrica la revolución social". La crisis había mostrado todos los límites del proceso de modernización de la sociedad argentina, lo cual auguraba un futuro sombrío:

\begin{abstract}
Desde la crisis, todo ha retrocedido, incluso el movimiento obrero, también las asociaciones de trabajadores, también las publicaciones de trabajadores. Por tal razón, revela miopía nuestro colega El Obrero cuando le reprocha al Vorwärts el hecho de encontrarse hoy muy lejos de su anterior nivel. Pero El Obrero puede convencerse de que el estado de los abonos del Vorwärts no se ha reducido en centenares desde aquella gloriosa época; no es, pues, un estado tan peligroso, y el Vorwärts dispondría incluso de un pequeño excedente si no tuviera que contar con diversos 'reclutas inseguros'. Por el contrario, El Obrero habría experimentado una muerte serena si no hubiera recibido entonces los mil pesos que le devolvieron la vitalidad. Pero en cuanto la suma se gaste, volverá a caer en la agonía, y con ello también la Federación imaginaria. En lo que atañe al líder intelectual de la F.O. y de El Obrero, sin el cual ambos desaparecerían sin dejar huella, hay que decir que éste no ha visto aún la F.O. que tan obstinadamente defiende. Es un hombre muy erudito, pero gris es toda teoría. Él juzga el mundo desde su punto de vista teórico, desde su cuarto de estudio. No podemos ponernos a la altura de su nivel teórico; A cambio, creemos poseer más common sense, o más sano sentido común. [...] Y vemos también que los diligentes empeños de una media docena de fanáticos germanoparlantes que creen estar aún en Alemania no han sido coronados, desgraciadamente, por el menor éxito. Decimos 'desgraciadamente' porque es triste que alguien no perciba que está sacrificándose inútilmente. ${ }^{29}$
\end{abstract}

\footnotetext{
${ }^{27}$ La obra de propaganda de la Federación Obrera y el Vorwärts, El Obrero, n. 54, 30 jan.1892.

${ }^{28}$ Die Arbeiterbewegung in Argentinien, Vorwärts, n. 265, 30 jan. 1892.

29 Die Arbeiterbewegung in Argentinien, Vorwärts, n. 265, 30 jan. 1892.
} 


\section{Conclusión. El Fin de Una Etapa}

La polémica entablada en 1891-1892 entre el nuevo equipo editorial del Vorwärts y el grupo vinculado a Lallemant y editor de El Obrero permite analizar las principales posturas que estaban en juego en esos primeros años del movimiento socialista en la Argentina. Pone de manifiesto el rol fundamental jugado por Lallemant en la organización de la primera federación obrera y en la edición del primer periódico socialista en español, así como el esfuerzo desarrollado por el grupo de socialistas alemanes, en su mayoría - que publicaron el periódico durante casi dos años. Permite asimismo matizar las interpretaciones que quisieron ver en Lallemant -sobre todo a partir de un análisis unilateral de las polémicas con los anarquistas- un defensor de perspectivas "objetivistas" y desinteresado en el rol "subjetivo" jugado por la acción de los militantes socialistas en el seno del movimiento.

Por otro lado, un examen de las críticas realizadas por el Vorwärts contribuye a enriquecer nuestro conocimiento sobre el desarrollo de las divisiones y debates que se dieron al interior del amplio grupo de socialistas alemanes en los orígenes del socialismo argentino. El alejamiento de J osé Winiger - emigrado a Brasil en 1890- y el cambio de dirección en mayo/junio de 1891, cuando Adolf Uhle fue reemplazado por Oswald Seyffert, produjeron un cambio en la orientación política del Vorwärts, al mismo tiempo que la profundización de la crisis económica y el reflujo del movimiento obrero que ella ocasionó abrían una crisis en el incipiente movimiento obrero socialista.

En efecto, la caracterización del Vorwärts sobre el futuro de la Federación -y, en conjunto, toda la polémica - tenían algo de profético: la profundización de la crisis llevaría, en la segunda mitad de 1892, a la desaparición de El Obrero y a la disolución de la Federación después de la realización de un Segundo Congreso en el cual la participación de sociedades gremiales había menguado hasta casi desaparecer. El último número de la primera etapa de El Obrero apareció el 24 de septiembre de 1892. Pocas semanas después, el Segundo congreso de la Federación obrera aprobaba un "Programa de acción", escrito por Augusto Kühn, inspirado en los partidos socialdemócratas europeos y se establecía "la toma del poder político por parte de la clase obrera".

La definición política era la contracara, sin embargo, de una Federación muy debilitada. En la práctica, sólo la mantenía en pie el esfuerzo de los militantes de la llamada Sección Varia, cuyos miembros eran, prácticamente en su totalidad, socialistas. El intento de construir una organización gremial con una definición política socialdemócrata había llegado a un límite, en el marco de la crisis económica, las luchas políticas con los anarquistas y las divergencias entre los propios emigrados alemanes. 
Así las cosas, en diciembre de 1892 la Federación se declaró disuelta y los militantes agrupados en la Sección Varia decidieron, por mayoría, transformarse en la Agrupación Socialista de Buenos Aires. Un grupo minoritario, cuyos principales referentes eran el alemán Gustav Nohke y el español Esteban J iménez, se opuso a la decisión y defendió la necesidad de continuar con la organización de una federación obrera. ${ }^{30}$

El año 1893 marca el punto más álgido del reflujo obrero y también del incipiente movimiento socialista argentino. A partir de abril de 1894, con la aparición de La Vanguardia y en el marco de un reanimamiento de la lucha obrera y gremial, se abre un nuevo período en el cual la figura dominante del socialismo argentino será J uan B. J usto y los socialistas alemanes - si bien continuaron activos, y varios de ellos tuvieron roles destacados- ya no tendrán una participación tan decisiva.

\section{Referencias}

ARICÓ, J osé. La hipótesis de J usto. Escritos sobre el socialismo en América Latina. Buenos Aires: Sudamericana, 1999.

CAMARERO, Hernán; Carlos Miguel HERRERA. El Partido Socialista en Argentina. Nudos históricos y perspectivas historiográficas. In: . El Partido Socialista en Argentina. Sociedad, política eideas a través de un siglo. Prometeo: Buenos Aires, 2005.

CÚNEO, Dardo. J uan B. J usto y las luchas sociales en la Argentina. Buenos Aires: Americalee, 1943.

DICKMANN, Enrique. Recuerdos de un militante socialista. Buenos Aires: Claridad, 1949.

DORFMAN, Adolfo. Historia de la industria argentina. Buenos Aires: Hyspamérica, 1986.

GARCÍA COSTA, Víctor. El Obrero: selección de textos. Buenos Aires: CEAL, 1985.

FALCÓN, Ricardo. Los orígenes del movimiento obrero (1857-1899). Buenos Aires: CEAL, 1984.

KLIMA, J an. La asociación bonaerense Vorwärts en los años ochenta del siglo pasado. Ibero-Americana Pragensia, Praga, v. 8, 1974.

KÜHN, Augusto. Apuntes para la historia del movimiento obrero socialista en la República Argentina. Tiempos Nuevos, n. 1-7, 1916.

KÜHN, Augusto. Páginas de la historia revolucionaria argentina. Espigando. Correspondencia Sudamericana, Buenos Aires, año 1, n. 2, abr. 1926.

30 La crisis de la primera Federación obrera y su disolución han sido trabajadas por la historiografía. Tarcus (2007, p. 276-278), Oddone (1949, p. 117-120) y Marotta (1975, p. 101-102). 
MAROTTA, Sebastián. El movimiento sindical argentino. Su génesis y desarrollo. 1857-1907. Buenos Aires: Libera, 1975.

MARTÍNEZ MAZZOLA, Ricardo. Campeones del proletariado. El Obrero y los comienzos del socialismo en la Argentina. Políticas de la Memoria. Anuario de investigación einformación del CeDInCI, n. 4, 2004.

PASO, Leonardo (Ed.). La clase obrera y el nacimiento del marxismo en la Argentina. Buenos Aires: Testimonios, 1974.

ODDONE, J acinto. Historia del Socialismo Argentino. Buenos Aires: Talleres Gráficos La Vanguardia, 1934.

RATZER, J osé. Los marxistas argentinos del 90. Córdoba: Pasado y Presente, 1970.

TARCUS, Horacio. ¿Un marxismo sin sujeto? El naturalista Germán Avé-Lallemant y su recepción de Karl Marx en la década de 1890. Políticas de la Memoria. Anuario de investigación einformación del CeDInCI, n. 4, 2004.

TARCUS, Horacio. Entre Lasalle y Marx. Los exiliados alemanes en la Argentina de 1890 y la recepción del socialismo europeo. Políticas de la Memoria. Anuario de investigación einformación del CeDInCI, n. 5, 2007a.

TARCUS, Horacio. Marx en la Argentina. Sus primeros lectores obreros, intelectuales y científicos. Buenos Aires: Siglo XXI, 2007b.

TARCUS, Horacio (Dir.). Diccionario biográfico de la izquierda argentina. Buenos Aires: Emecé, 2008.

ZELLER, J essica. Entre la tradición y la innovación. La experiencia del Vorwärts en Buenos Aires. Políticas de la Memoria. Anuario de investigación e información del CeDInCI, n. 5, 2007.

ZELLER, J essica, Sandra Carreras; TARCUS, Horacio. Die deutschen Sozialisten und die Anfänge der argentinischen Arbeiterbewegung: Antologie des Vorwärts, (Buenos Aires 1886 - 1901) / Los socialistas alemanes y la formación del movimiento obrero argentino: Antología del Vorwärts, (1886 - 1901). Buenos Aires: CeDInCI Editores/ Buenos Libros, 2008.

ZARAGOZA, Gonzalo. Anarquismo argentino 1876-1902. Madrid: Ediciones de la Torre, 1996. 